\title{
Review
}

\section{iPSCs and small molecules: a reciprocal effort towards better approaches for drug discovery}

\author{
Ru ZHANG ${ }^{1}$, Li-hong ZHANG ${ }^{2}$, Xin XIE ${ }^{1,2, *}$ \\ ${ }^{1}$ Laboratory of Receptor-based Bio-medicine, Shanghai Key Laboratory of Signaling and Disease Research, School of Life Sciences \\ and Technology, Tongji University, Shanghai 200092, China; ${ }^{2}$ CAS Key Laboratory of Receptor Research, the National Center for Drug \\ Screening, Shanghai Institute of Materia Medica, Chinese Academy of Sciences, Shanghai 201203, China
}

\begin{abstract}
The revolutionary induced pluripotent stem cell (iPSC) technology provides a new path for cell replacement therapies and drug screening. Patient-specific iPSCs and subsequent differentiated cells manifesting disease phenotypes will finally position human disease pathology at the core of drug discovery. Cells used to test the toxic effects of drugs can also be generated from normal iPSCs and provide a much more accurate and cost-effective system than many animal models. Here, we highlight the recent progress in iPSC-based cell therapy, disease modeling and drug evaluations. In addition, we discuss the use of small molecule drugs to improve the generation of iPSCs and understand the reprogramming mechanism. It is foreseeable that the interplay between iPSC technology and small molecule compounds will push forward the applications of iPSC-based therapy and screening systems in the real world and eventually revolutionize the methods used to treat diseases.
\end{abstract}

Keywords: induced pluripotent stem cells (iPSCs); disease modeling; drug screening; toxicity evaluation; cell replacement therapy; small molecules; drug development

Acta Pharmacologica Sinica (2013) 34: 765-776; doi: 10.1038/aps.2013.21; published online 22 Apr 2013

\section{Introduction}

The development of human society is always accompanied by the evolution of diseases. Many diseases, especially degenerative disorders, still lack effective cures. In recent decades, the progress in stem cell research has provided new hope for cell replacement therapies and new methods to identify drugs. Stem cells can be roughly separated into two categories. The first type, adult stem cells, or organ-specific stem cells, generally have limited potential for growth and differentiation, whereas the second type, embryonic stem cells (ESCs), can be cultured in vitro indefinitely and can theoretically give rise to all cell types. The recent discovery of induced pluripotent stem cells (iPSCs) has created even more enthusiasm for exploring the therapeutic potential of stem cells in regenerative medicine because iPSCs overcome the ethical and histocompatibility issues hampering the use of human ESCs ${ }^{[1,2]}$.

In contrast to human ESCs, iPSCs can be generated with direct reprogramming of adult skin cells (or other easily obtainable adult cells) with defined transcription factors (Oct4, Sox2, Klf4, c-Myc, etc), indicating that every person could have

\footnotetext{
* To whom correspondence should be addressed. E-mail xxie@mail.shcnc.ac.cn

Received 2012-12-31 Accepted 2013-02-07
}

his/her own iPSCs ${ }^{[1-3]}$. iPSCs derived from patients, especially patients carrying disease-related genetic mutations, should retain these mutations and be able to give rise to cells that harbor the disease phenotype ${ }^{[4-8]}$. These disease-carrying iPSCs could be genetically corrected in vitro, differentiated into the appropriate cell types, and transferred back into patients to support normal physiological functions ${ }^{[6,7]}$, or these diseasecarrying cells could be used as in vitro models to study the mechanisms of the disease or serve as tools to screen for new small-molecule drugs ${ }^{[4,5,8]}$.

On the other hand, the existing small-molecule drugs also have helped to advance iPSC technology and dissect the underlying mechanisms of somatic cell reprogramming. Although iPSCs have enormous potential, the clinical application of iPSC technology is still hindered by safety concerns and relatively low efficiency. To prevent the use of oncogenes and the incorporation of viral DNA sequences, considerable effort has been expended to modify the original reprogramming protocols by using a reduced number of factors ${ }^{[9]}$, non-integrating gene delivery approaches ${ }^{[10]}$, and cell-permeable proteins to trigger the reprogramming ${ }^{[11]}$. Small molecules, due to their ease of use and structural versatility, have attracted considerable interest for steering reprogramming towards a faster, more efficient, and directed process. 
In this review, we discuss the therapeutic potential of iPSCs, focusing on iPSC-based cell therapy, disease modeling and drug evaluations. In addition, we discuss the use of small-molecule drugs to improve the generation of iPSCs and understand the reprogramming mechanism. Hopefully, the interplay between iPSC technology and small-molecule compounds will facilitate the development of new therapies.

\section{iPSC-based cell therapy}

One of the most exciting aspects of iPSC technology is the possibility of generating autologous cells for cell-replacement therapy. The somatic origin of iPSCs has minimized the ethical concerns and greatly reduced the immune rejection problems that have hampered the development of human ESCbased therapies. Hanna and colleagues ${ }^{[6]}$ demonstrated for the first time that iPSCs derived from a humanized mouse model of sickle cell anemia could be genetically corrected, differentiated into hematopoietic progenitor cells in vitro, and then transplanted back into the original mice, resulting in an improved phenotype. Raya et al generated genetically corrected iPSCs from patients with Fanconi's anemia (FA), and the hematopoietic progenitor cells derived from these iPSCs demonstrated functional FA pathway reestablishment in vitro $^{[7]}$.

Similar cell-replacement strategies have been reported for other organs and implemented in many other disease models. For example, Wernig and colleagues ${ }^{[12]}$ successfully derived functional dopaminergic neurons from iPSCs, and the transplantation of these neurons into a rat model of Parkinson's disease (PD) resulted in normalized dopamine activity and alleviation of PD symptoms. Neurospheres produced by iPSCs have been transplanted into the brain of a spinal-cord injury mouse model, and functional recovery was confirmed with accompanying re-myelination and axonal regrowth ${ }^{[13]}$. Transplantation of factor VIII (FVIII)-producing endothelial cells derived from iPSCs has been reported to rescue mice carrying hemophilia A (caused by a mutation in FVIII) from a deathinducing bleeding assay ${ }^{[14]}$. In addition, iPSCs have also been differentiated into functional cardiac myocytes ${ }^{[15]}$, and humaniPSC-derived cardiac myocytes have been shown to improve the cardiac contractile function in the experimentally injured rodent heart ${ }^{[16,17]}$. Mouse iPSC-derived mature $\beta$ cells generated from chimeric animals were used to rescue syngeneic diabetic mice induced with streptozotocin ${ }^{[18]}$. Insulin-producing cells have also been generated from human iPSCs ${ }^{[19]}$, and the function of these cells has been confirmed in a mouse model of type I diabetes ${ }^{[20]}$.

Although the therapeutic effects of stem cells have been proven in many animal models, the ESC or iPSC-based cell therapy is still hindered by safety concerns regarding tumor formation and technical difficulties in generating large quantities of pure, well-differentiated and functional cells. Nevertheless, the generation of differentiated cells or tissues from patient-specific iPSCs may provide a new approach for disease modeling and drug screening in vitro.

\section{iPSC-based disease modeling and drug screening}

The average time required to develop a new drug is between 10 and 15 years, and the associated costs can reach one billion $\mathrm{USD}^{[21]}$. More than $90 \%$ of the drugs tested in clinical trials fail to be approved because of a lack of sufficient efficacy or unanticipated toxicity ${ }^{[22]}$. Discovering new effective entities and evaluating their safety are two key aspects of developing new drugs. The success of preclinical phases of drug development is largely based on animal models, which might fail to translate into real human diseases. Disease or screening models that faithfully represent actual human diseases or human physiology are needed to improve the success rate of drug discovery and development. Drug discovery/development platforms using iPSC-based disease models could be useful in filling the gap between animal models and clinical trials.

Several hurdles must be overcome to apply iPSCs to drug discovery. First, iPSCs must be generated from nonpluripotent patient cells, and then, these patient specific iPSCs have to be differentiated into the mature cells that express the diseaserelevant cellular pathology, a key step and major challenge in "disease modeling". Based on these disease phenotype-expressing cells, we can screen for novel compounds that might correct the cellular pathology or evaluate possible toxicity of drugs. Although theoretically appealing, modeling diseases that are more genetically complex, such as sporadic Alzheimer's disease (AD), remain challenging. To date, only partial disease modeling has been reported, mostly for monogenic disorders. Nevertheless, these not-so-perfect disease models could still be important and relevant, especially in situations when animal models do not recapitulate the actual human diseases.

\section{Neurological diseases}

Neurological disorders account for $6.3 \%$ of the global burden of diseases ${ }^{[23]}$, and this burden is expected to increase as the human life span is extended. Most neurological disorders are caused by the dysfunction or loss of specific populations of neuronal and/or glial cells. As human neurons and glia are not readily available, studies have been traditionally limited to genetically engineered animal models or cell lines less relevant to the disease pathophysiology. The introduction of iPSC technology has provided a new approach for the study of neurological disorders at a cellular level.

Spinal muscular atrophy (SMA), familial dysautonomia (FD) and Rett syndrome (RS) are early onset monogenic disorders that provide a relatively easy start point for iPSC-based disease modeling. SMA is the most common neurogenetic disorder of infancy. The disease is caused by deletions of the SMN1 gene, resulting in a decreased level of survival of motor neuron (SMN) protein, which eventually leads to the loss of motor neurons and the consequent denervation of the axial and limb muscles. This loss manifests clinically as muscle atrophy and weakness, dysphagia and respiratory failure in severe cases ${ }^{[24]}$. Researchers have screened for compounds that elevate SMN levels in various engineered cell lines and patient fibroblasts, 
but these compounds have failed in the clinic possibly because the mechanisms that regulate SMN protein levels in fibroblasts or engineered cells are substantially different from those in human motor neurons in vivo. Ebert and colleagues created two iPSC lines ${ }^{[25]}$ and demonstrated that SMA motor neurons derived from iPSCs developed normally but were more susceptible to degeneration accompanied by a reduction in SMN aggregates. Two drugs, valproic acid(VPA) and tobramycin, have been found to increase the number of SMN-rich structures in the SMA iPSCs. Although it remains to be seen whether these compounds can have the same effect in patient motor neurons, these early studies provide an important validation of the utility of iPSC-derived patient cells to model the disease.

FD is caused by mutations in the IKBKAP gene ${ }^{[26]}$ that lead to the abnormal migration of neural crest cells and results in the loss of sensory, sympathetic and parasympathetic neurons. In a recent study, Lee and colleagues derived iPSCs from three young patients with FD and induced the differentiation of these iPSCs into neural crest cells ${ }^{[4]}$. Several diseaserelated defects were confirmed in these neural crest cells: a splicing defect in IKBKAP, a cellular migration defect and a defect in neurogenesis. The researchers also reported that the small molecule kinetin markedly reduced the splicing defect and modestly affected neurogenesis but had no effect on cell migration. Gene expression profiling of the FD neural crest cells also identified genes involved in peripheral neurogenesis and neuronal differentiation, providing insight into the molecular mechanisms of the disease. This study confirmed the application of iPSC-based cell models in phenotypic drug screens and for the identification of novel mechanisms and molecular targets.

Another developmental neurological disease, RS, is caused by the mutations in methyl-CpG-binding protein 2 (MeCP2), a protein involved in DNA methylation ${ }^{[27]}$. iPSCs from RS patients have also been generated and differentiated into GABAergic neurons ${ }^{[5]}$. Although no obvious changes in neurogenesis were observed, a reduction in the number of synaptic spines, a phenomenon observed in the post-mortem brains of RS patients, was reported. Calcium oscillations and the frequency of spontaneous postsynaptic currents were also decreased in neurons derived from RS iPSCs, suggesting a decreased neuronal networking activity. Using these cells, the authors also identified compounds that partially rescued the disease phenotype. Another study from the same group demonstrated that neural cells derived from RS iPSCs manifest increased L1 transposon motility, providing another mechanism that may underlie the disease and a novel target for drug discovery ${ }^{[8]}$.

Amyotrophic lateral sclerosis (ALS) and PD are late-onset neurological disorders. ALS is a fatal motor neuron disease, characterized by the progressive loss of motor neurons and muscle atrophy. Only approximately $10 \%$ of the patients have a genetic etiology, which makes modeling the disease more difficult. To date, several iPSC lines have been established from ALS patients carrying a SOD1 point mutation ${ }^{[28,29]}$, and functional motor neurons have been generated. However, unfortunately, the ALS-specific phenotype has yet to be determined. PD, the second most common neurodegenerative disorder, is caused by the progressive loss of dopaminergic neurons in midbrain. Although the symptom can be initially controlled, the progressive neurodegeneration will eventually lead to the loss of therapeutic efficacy. iPSCs have been established and used for in vitro disease modeling for two types of familial PD. iPSCs carrying the mutation in the gene encoding leucine-rich repeat kinase 2 (LRRK2), the most common cause of familial PD, were derived by Nguyen et $a l^{[30]}$. The iPSC-derived dopaminergic neurons displayed increased a-synuclein level and sensitivity towards environmental stress. Dopaminergic neurons generated from iPSCs carrying mutations in the gene encoding PTEN-induced putative kinase 1 (PINK1) exhibited impaired recruitment of Parkin, another protein associated with familial PD and mitochondrial dysfunction that could be corrected by introduction of wild-type $P I N K 1^{[31]}$. It remains to be determined whether these anomalies also exist in dopaminergic neurons derived from patients with sporadic PD and thus providing common mechanisms and targets for drug discovery and development.

Disease modeling based on iPSC technology has also been applied to many other neurological or psychiatry disorders, including Alzheimer's disease ${ }^{[32]}$, Huntington's disease ${ }^{[33,34]}$, Angelman and Prader-Willi syndromes ${ }^{[35,36]}$, schizophrenia ${ }^{[37]}$, and others (Table 1$)$.

\section{Cardiovascular diseases}

Heart disease, caused by both environmental and genetic factors, is the leading cause of death in many countries. More than 40 cardiovascular disorders, including hypertrophic cardiomyopathy, inherited arrhythmias such as familial long QT syndrome (LQTS), short QT syndrome and conduction system disorders, are caused by single gene mutations ${ }^{[38]}$. Similar to neurological disorders, the limited availability of human cardiomyocytes is a major obstacle for replacement therapy and drug discovery and development. Many studies are still relying on the use of animal models and non-human cardiomyocytes. Human iPSC-derived cardiomyocytes offer an unprecedented opportunity to establish patient-specific lineages for disease modeling and drug screening. To date, both hypertrophic cardiomyopathy and cardiac channelopathy have been modeled using cardiomyocytes derived from patient iPSCs.

Carvajal-Vergara and colleagues ${ }^{[39]}$ generated two iPSC lines from two patients with LEOPARD syndrome (LS), who carry a heterozygous T468M mutation in PTPN11 (protein tyrosine phosphatase, non-receptor type 11). LEOPARD is the acronym for its main features: lentigines, electrocardiographic abnormalities, ocular hypertelorism, pulmonary valve stenosis, abnormal genitalia, retardation of growth and deafness. Among these features, hypertrophic cardiomyopathy is the most life threatening. Interestingly, in vitro differentiated cardiomyocytes from LS iPSCs are larger and have a higher degree of sarcomeric organization and nuclear localization of NFATC (nuclear factor of activated T-cells, cytoplasmic, 
Table 1. Summary of iPSC-based disease modeling and drug evaluation.

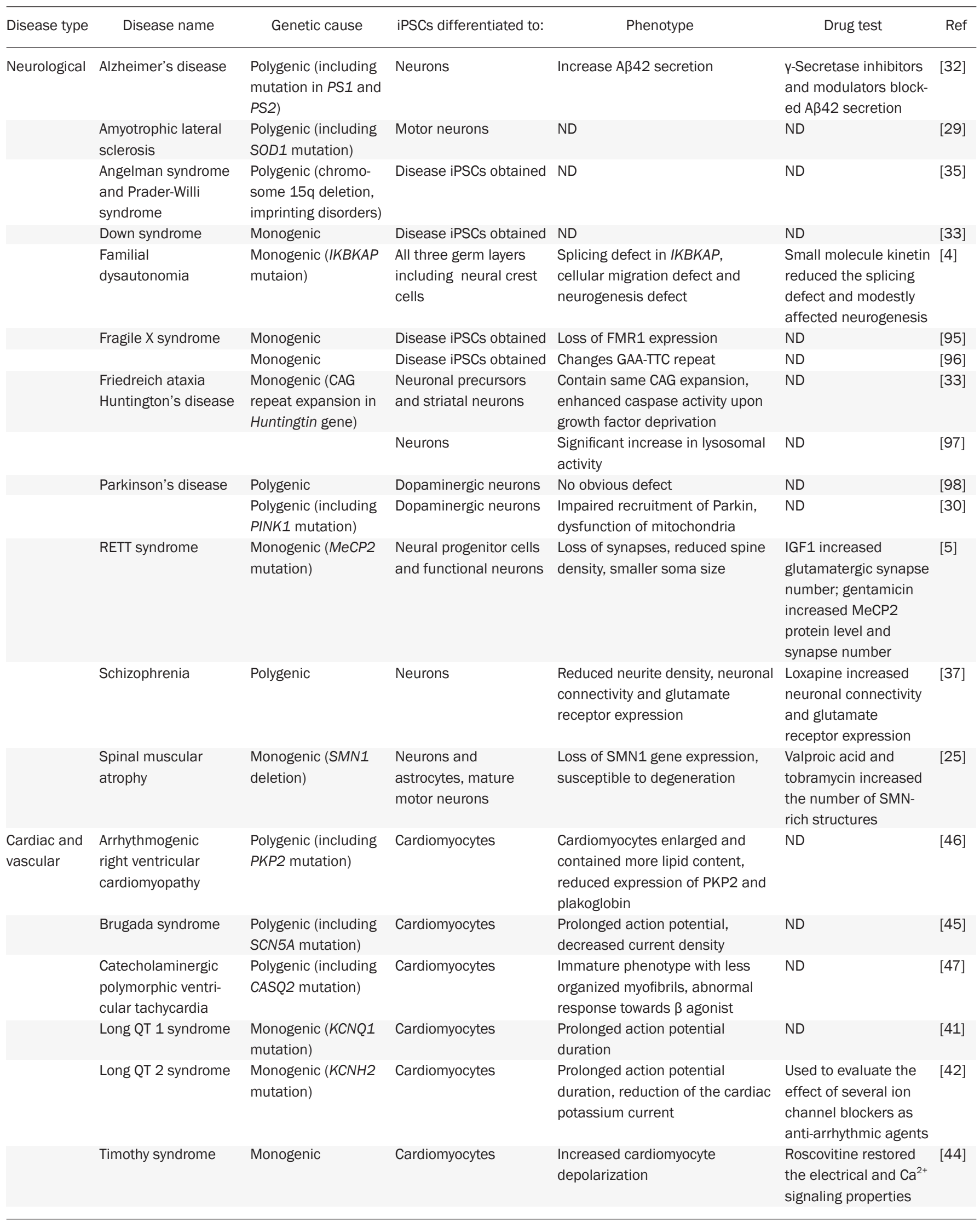




\begin{tabular}{|c|c|c|c|c|c|c|}
\hline Disease type & Disease name & Genetic cause & iPSCs differentiated to: & Phenotype & Drug test & Ref \\
\hline & LEOPARD syndrome & $\begin{array}{l}\text { Monogenic (PTPN11 } \\
\text { mutation) }\end{array}$ & Cardiomyocytes & $\begin{array}{l}\text { Increased cardiomyocyte size, } \\
\text { higher degree of sarcomeric } \\
\text { organization and nuclear } \\
\text { localization of NFATC }\end{array}$ & ND & [39] \\
\hline \multirow[t]{3}{*}{$\begin{array}{l}\text { Others } \\
\text { diseases }\end{array}$} & $\begin{array}{l}\text { A1-antitrypsin } \\
\text { deficiency }\end{array}$ & Monogenic & Liver cell & Loss of A1-antitrypsin expression & ND & {$[53]$} \\
\hline & Diabetes & $\begin{array}{l}\text { Polygenic (with } \\
\text { mitochondrial DNA } \\
\text { A3243G mutation) }\end{array}$ & Disease iPSCs obtained & ND & ND & [99] \\
\hline & $\begin{array}{l}\text { Fibrodysplasia } \\
\text { ossificans progressiva }\end{array}$ & $\begin{array}{l}\text { Monogenic (ALK2 } \\
\text { mutation) }\end{array}$ & Disease iPSCs obtained & $\begin{array}{l}\text { Constitutive activation of ALK2, } \\
\text { blocking reprogramming }\end{array}$ & $\begin{array}{l}\text { ALK2 inhibitors } \\
\text { rescued } \\
\text { reprogramming }\end{array}$ & {$[100]$} \\
\hline
\end{tabular}

ND: not determined.

calcineurin-dependent).

LQTS, a common type of cardiac arrhythmia, is mainly caused by mutations of the genes encoding ion channels. Mutations in the voltage-gated $\mathrm{K}^{+}$channels genes, including KCNQ1 and KCNH2, lead to type 1 and type 2 LQTS, respectively, whereas mutations in the voltage-gated $\mathrm{Na}^{+}$channel gene SCN5A lead to type $3 \mathrm{LQTS}^{[40]}$. Moretti et al generated cardiomyocytes from iPSCs derived from patients with familial type 1 LQTS carrying a R190Q mutation in the KCNQ1 gene $^{[41]}$. These cells exhibited prolonged action potential duration and were able to recapitulate the electrophysiological phenotype of this disorder. Two studies have demonstrated the successful generation of iPSCs from type 2 LQTS patients carrying A614V or G1681A mutations in the KCNH2 gene ${ }^{[42,43]}$. Cardiomyocytes differentiated from these iPSCs displayed significant prolongation of the action potential duration; this phenomenon was caused by a reduction of the cardiac potassium current. These cells have also been used to evaluate the effect of several ion-channel blockers as anti-arrhythmic agents. An iPSC-based model of LQTS in Timothy syndrome (TS) patients has also been reported. TS is caused by a mutation in the gene encoding the main L-type channel in the mammalian heart ${ }^{[44]}$. Cardiomyocytes from these iPSCs displayed the molecular hall marks of LQTS, and treatment with roscovitine restored their electrical and $\mathrm{Ca}^{2+}$-signaling properties.

Disease-specific iPSCs have also been generated from other heart diseases such as Brugada syndrome ${ }^{[45]}$, arrhythmogenic right ventricular cardiomyopathy ${ }^{[46]}$ and catecholaminergic polymorphic ventricular tachycardia ${ }^{[47]}$ (Table 1 ). Similar to the studies focused on neurological disorders, these studies not only support the use of the iPSC-derived cardiomyocytes to model the abnormal functional phenotype of inherited cardiac disorders in vitro but also demonstrate the possibility of using these cells to screen existing or experimental drugs. However, the modeling of adult-onset diseases remains a challenge for iPSC-derived cells because aging or environmentally triggered diseases may be mediated by epigenetic modifications of certain genes, and these modifications are reset with current iPSC technology.

\section{iPSC-based toxicity evaluation}

The attrition rate of drugs in development for humans, much of which can be attributed to unforeseen toxic side effects, mainly cardiotoxicity and hepatotoxicity ${ }^{[48]}$ that were not observed in preclinical animal models, is a significant problem facing the pharmaceutical industry. Approximately $30 \%$ of the medicines that have entered clinical trials were abandoned because of a lack of efficacy and another $30 \%$ were halted because of safety concerns ${ }^{[49]}$. Predictive in vitro toxicity assays with adequate accuracy would help to reduce the failure rate and thus the cost of drug development. The use of human iPSCs and iPSC-derived cardiomyocytes and hepatocytes should be able to provide straightforward assays for analyzing many aspects of drug metabolism and toxic side effects.

The heart has been proven to be particularly sensitive to off-target, life-threatening toxic effects of non-cardiac drugs. Over the past decade, unexpected drug-induced ventricular arrhythmias associated with sudden cardiac death has led to the withdrawal of a number of drugs from the market ${ }^{[50]}$, among them the famous non-steroidal anti-inflammatory drug Vioxx from Merck. The blockade of the ether-a-go-go-related gene 1 ( $h E R G 1$, also named KCNH2) channel is one of the major causes of drug-induced LQTS. Though it is still difficult to obtain pure mature cardiomyocytes for drug toxicity studies, significant progress has been made. Normal responses towards $\beta$-adrenergic and muscarinic stimulations have been demonstrated in human iPSC-derived cardiomyocytes by several studies ${ }^{[17,51,52]}$, indicating normal functions of these cells. It is foreseeable that in the near future, cardiac toxicity screenings based on these cells will soon become a valuable tool for the early evaluation of drug toxicity.

For drug metabolism and toxicity studies, primary human 
hepatocytes are still the golden standard of in vitro models, as they express the full spectrum of drug metabolizing enzymes and transporters. However, the availability of primary human hepatocytes and batch-to-batch variation can lead to unnecessary complications. Human iPSC-derived hepatocytes will not only provide a scalable supply of cells for general metabolism and toxicity studies but will also enable the study of drug effects across a broad spectrum of hepatocytes lines that might contain the genetic variations of the human population. For example, P450 polymorphism is the main cause of metabolism and toxicity variation of drugs in humans. Hepatocytes derived from iPSCs carrying these polymorphisms would be of great value for early drug safety evaluation. Although several inherited hepatic diseases have been successfully modeled in vitro by hepatocytes derived from patient-specific iPSCs ${ }^{[33,54]}$, the current differentiation protocols are still lacking in terms of generating highly pure and phenotypic stable hepatocytes. The use of three-dimensional culture and co-culture systems to mimic the in vivo hepatic context are among the strategies used to enhance the generation of hepatocytes ${ }^{[49]}$. Given the continuous effort devoted to improve the differentiation methods, the future of applying iPSC-derived hepatocytes in drug screening and safety evaluation is promising.

\section{Small molecules promoting iPSC generation}

Although iPSCs have enormous potential, the clinical application of iPSC technology is still hindered by safety concerns and relatively low efficiency. In addition, the exact mechanisms underlying somatic cell reprogramming also remain to be elucidated. Considerable effort has been expended to modify the original reprogramming protocol, including using reduced number of factors ${ }^{[9]}$, non-integrating gene delivery approaches ${ }^{[10]}$, or cell permeable proteins to trigger the reprogramming $^{[11]}$, to improve safety and make the iPSCs more amendable for clinical use. Compared to the aforementioned methods, small-molecule drugs have several unique advantages, such as structural versatility and being easy to control in a time- and concentration-dependent way. Many small molecules have been found to be extremely useful in steering reprogramming toward a faster, more efficient, and directed process (Table 2).

\section{Epigenetic modifiers}

Epigenetic mechanisms preside over our genetic information and enable the normal development of all cells and tissues in our body. The reprogramming process demonstrates the profound flexibility of the mammalian epigenome, indicating modulators of epigenome are critically involved in iPSC generation $^{[55]}$. Accordingly, small molecules that directly modulate the epigenetic enzymes or mechanisms, which in turn change DNA or histone modifications, have been demonstrated to affect reprogramming. Histone deacetylase inhibitors (HDACi) and DNA methyltransferase inhibitors are among the earliest discovered compounds that facilitate the generation of iPSCs ${ }^{[56]}$.

In particular, one study demonstrated that VPA, an HDACi, improves 4-factor-mediated reprogramming efficiency by more than 100-fold ${ }^{[56]}$. VPA, vorinostat(suberoylanilide hydroxamic acid, SAHA), and Trichostatin A (TSA) also improve the induction efficiency of mouse and human iPSCs with reduced numbers of factors (Oct4 and Sox2) ${ }^{[56,57]}$. Furthermore, VPA allowed successful generation of iPSCs with only recombinant proteins and without any genetic materials $^{[11]}$. BIX-01294 (BIX), a small-molecule inhibitor of histone methyltransferase (HMTase), G9a, has been demonstrated to significantly enhance the reprogramming efficiency and replace some of the transcription factors required for reprogramming ${ }^{[58]}$. When BIX is combined with BayK8644, an L-calcium channel agonist, a synergistic increase in the number and size of iPSC colonies is observed. Other histone modification enzymes, such as LSD1 (a H3K4 demethylase), are also involved in reprogramming. Small molecules targeting LSD1, including parnate and $\mathrm{LiCl}$, have also been reported to facilitate iPSC induction ${ }^{[59,60]}$. In addition, Jhdm1a/1b, two known vitamin-C-dependent H3K36 demethylases, have been found to critically regulate vitamin C-enhanced reprogramming ${ }^{[61]}$.

DNA methylation is another common epigenetic mechanism involved in the expression regulation of genes. A DNA methyltransferase (DNMT) inhibitor, 5-azacytidine (5-aza), has been found to promote overall efficiency in the 4-factorinduced reprogramming of MEFs ${ }^{[56]}$. RG108, another DNMT inhibitor, enhanced the reprogramming efficiency of MEFs transduced with Oct4 and Klf4 in combination with BIX ${ }^{[58]}$. Recently, stress mediated-p38 activation has also been shown to facilitate iPSCs generation by reducing the global DNA methylation level ${ }^{[62]}$. It is also interesting to note that epigenetic modifiers not only improve the efficiency of reprogramming but also improve the quality of the resulting iPSCs. TSA and 5-aza have been shown to erase the epigenetic memory of somatic cells in early passage iPSCs ${ }^{[63,64]}$. TSA has also been used to activate the expression of the imprinted Dlk1-Dio3 locus ${ }^{[65,66]}$, which is critical to the pluripotency of iPSCs.

\section{MET/EMT modulators}

The mesenchymal to epithelial transition (MET) is critically involved in somatic cell reprogramming. The mesenchymaltype fibroblasts undergo dramatic morphological changes to form tightly packed iPSC clones with distinct cell-cell interaction and gene expression profiles ${ }^{[67]}$. Transforming growth factor $\beta$ (TGF $\beta$ ) is a prototypical cytokine involved in the induction of epithelial to mesenchymal transition (EMT), the opposite process of MET, which plays important roles in stem cell differentiation and tumor metastasis. Recent studies have demonstrated the importance of the inhibition of TGF $\beta$ signaling in the generation of mouse and human iPSCs. A-83-01, a small-molecule inhibitor of TGF $\beta$ receptor I kinase/ activin-like kinase 5 (ALK5), has been shown to be critical for the generation and maintenance of rat iPSCs in combination with the MEK and GSK-3 $\beta$ inhibitors ${ }^{[68]}$. Inhibiting the TGF $\beta$ pathway with other ALK5 inhibitors, including SB-431542 and E-616452 (RepSox), enables faster and more efficient induction of iPSCs and bypasses the requirement for exogenous c-Myc 
Table 2. Summary of small molecule compounds enhancing iPSC generation.

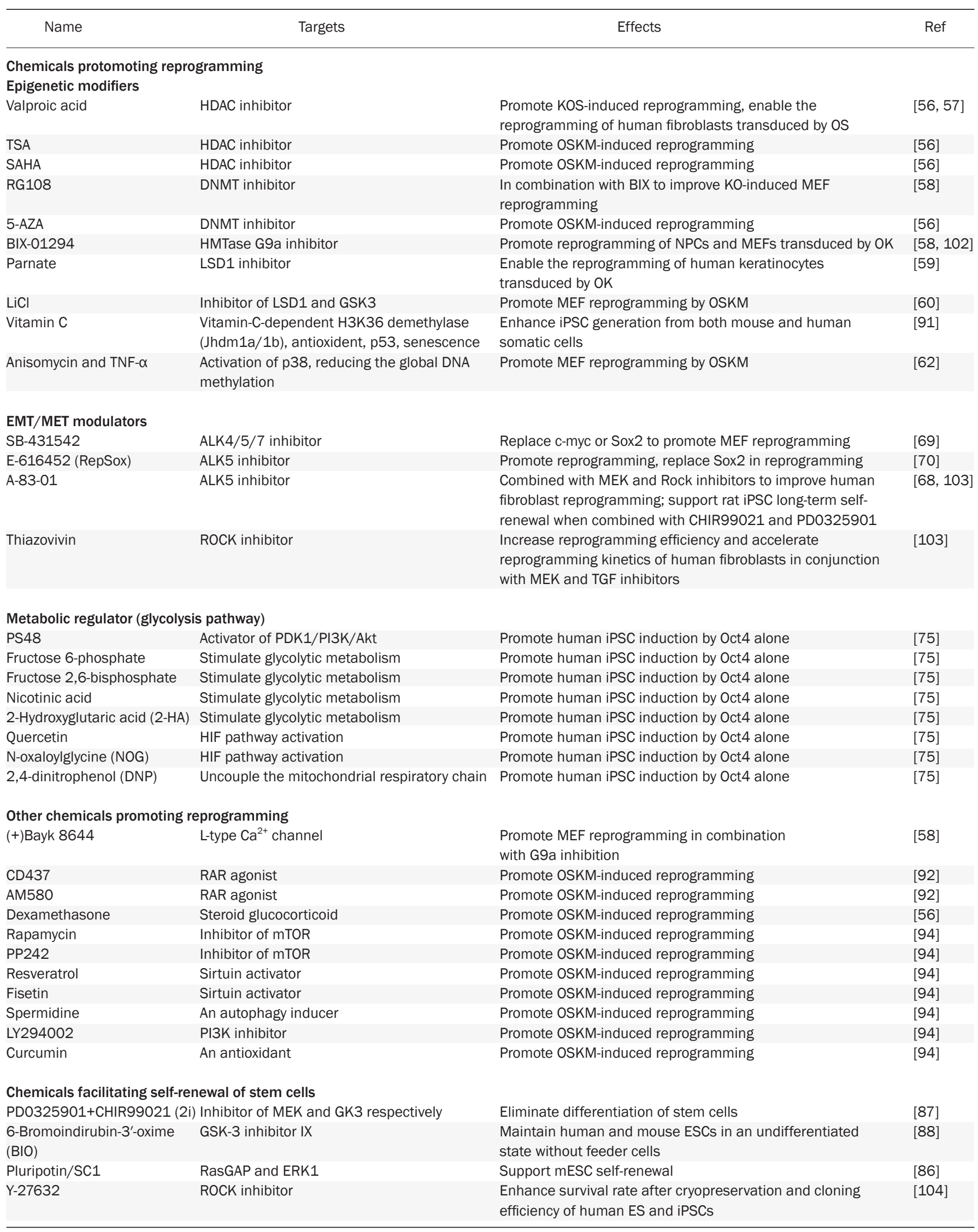


or Sox $2^{[69,70]}$.

The Wnt/ $\beta$-catenin pathway also plays important roles in EMT/MET induction. The activation of Wnt leads to GSK-3 $\beta$ inhibition and thus the stabilization of $\beta$-catenin. The activation of Wnt signaling by Wnt3a protein promotes iPSC generation from 3-factor (OSK) transduced $\mathrm{MEFs}^{[71]}$. The GSK-3 $\beta$ inhibitor CHIR99021, which strongly activates the $\beta$-catenin pathway, has been shown to be particularly useful in enhancing generation of mouse and human iPSCs without exogenous Sox2 and c-Myc ${ }^{[59]}$. CHIR99021 is also one of the components of the famous $2 \mathrm{i}$ (PD0325901 and CHIR99021), which is extremely useful not only in maintaining ESCs but also in facilitating the final transition of certain partially reprogrammed cells into real iPSCs ${ }^{[72]}$. Similarly, kenpaullone, a less specific GSK-3 $\beta$ inhibitor that also inhibits cyclin-dependent kinase (CDK) and other kinases, has been found to be capable of replacing exogenous Klf4 to reprogram MEFs transduced by $\mathrm{OSM}^{[73]}$.

\section{Metabolic regulators}

In most differentiated cells, energy is produced mainly by mitochondrial oxidative phosphorylation. In contrast, stem cells mainly rely on anaerobic glycolysis followed by lactic acid fermentation in the cytosol to produce energy and thus fewer reactive oxygen species are generated ${ }^{[74]}$. Consequently, the reprogramming of somatic cells that utilize mitochondrial oxidation to iPSCs would require a switch in metabolism. Therefore, small molecules modulating this process may enhance somatic cell reprogramming. PS48, an activator of 3-phosphoinositide-dependent protein kinase 1 (PDK1), significantly induces the expression of glycolytic genes via activation of PI3K/Akt pathway and facilitates human iPSC generation with one transcription factor Oct4 ${ }^{[75]}$. Although ESCs and iPSCs contain functional respiratory complexes that are able to consume oxygen, uncoupling protein 2 in these cells plays a critical role by preventing mitochondrial glucose oxidation and facilitating glycolysis ${ }^{[76]}$. Thus, small molecules that uncouple the mitochondrial respiratory chain may also promote reprogramming to iPSCs. 2,4-dinitro-phenol (DNP), a well-known uncoupler, significantly increases reprogramming efficiency ${ }^{[75]}$. The activation of the HIF pathway by $\mathrm{N}$-oxalylglycine and quercetin also enhances reprogramming by promoting glycolytic metabolism. In contrast, compounds such as oxalate that block glycolytic metabolism inhibit reprogramming $^{[75]}$. These studies reveal that metabolism switching is another fundamental mechanism in somatic cell reprogramming that can be used as a promising target for the screening of iPSC-promoting molecules.

\section{Small molecules promoting self-renewal of ESCs/iPSCs}

The successful generation of iPSCs can be roughly divided into two steps: the transition (reprogram) from somatic cells to iPSCs and the propagation/self-renewal of iPSCs. Therefore, it is easy to understand that the chemicals used to promote ESC self-renewal should also promote the generation of iPSCs. The establishment and maintenance of early mouse ESCs relied on feeder cells and serum ${ }^{[77,78]}$. In the effort to identify more defined conditions for mESC culture, several growth factors were identified as being critical for mESC self-renewal. LIF (leukemia inhibitory factor) produced by the feeder cells and BMP4 (bone morphogenetic protein 4), a key factor existing in the serum, were found to be essential for maintaining the proliferation potential of mESCs ${ }^{[79,80]}$. The maintenance of self-renewal can be viewed as a combination of continued proliferation and inhibition of differentiation through cross-talks among positive and negative regulators. LIF activates STAT3 to stimulate mESC proliferation, and BMP4 functions through SMAD to activate the inhibitors of differentiation. However, for human ESCs, other exogenous growth factors than LIF and BMP4 are required for their maintenance. For example, bFGF $^{[81,82]}$, TGF- $\beta /$ activin $\mathrm{A}^{[83,84]}$, Wnt ${ }^{[81]}$ proteins and insulinlike growth factor ${ }^{[85]}$ are reported to support the self-renewal of hESCs.

In addition to the growth factors, small molecules that can sustain the self-renewal of mESCs have been identified in more chemically defined conditions without feeder-, serum- and LIF supplementation. One example is pluripotin (also known as SC1 $)^{[86]}$, which does not directly act on the known pathways involved in ESC self-renewal, including LIF/STAT3, BMP/ SMAD/ID, and Wnt/ $\beta$-catenin pathways, but rather through the inhibition of RasGAP and extracellular-signal-regulated kinase 1 (ERK1), two proteins with differentiation-inducing activity. Smith and colleagues ${ }^{[87]}$ demonstrated that using a chemical combination (2i) of PD0325901, an ERK1/2 inhibitor, to eliminate differentiation-inducing signaling from mitogenactivated protein kinase (MAPK), and CHIR99021, a GSK-3 $\beta$ inhibitor to prevent MET, allows mESCs to maintain their innate program for self-replication, which does not require extrinsic instruction to maintain self-renewal ${ }^{[88]}$. Many of these growth factors and compounds have also been applied to the induction of human or mouse iPSCs. Compared with conventional culture conditions, chemically defined medium can eliminate the highly variable factors contributed by feeder cells and the undefined composition of serum products and thus benefit the maintenance of large-scale, consistent and robust long-term ESC/iPSC cultures as well as derivation of new cell lines from difficult strains or species.

\section{Other chemicals used in IPSC induction}

Other signal pathways involved in cell stress, senescence and DNA damage have also been demonstrated to play a role in iPSC induction. Cellular senescence is considered a barrier to reprogramming, and the expression of reprogramming factors somehow triggers senescence by upregulating p53, p16 ${ }^{\text {INK4a }}$, and $\mathrm{p} 21^{\mathrm{CIP} 1}$, which contribute to the extremely low efficiency and slow kinetics of reprogramming ${ }^{[89]}$. Blocking the p53 pathway greatly facilitates the generation of iPSCs ${ }^{[90]}$. Vitamin $\mathrm{C}$ improves the reprogramming efficiency at least partially by reducing the senescence triggered by the p53 pathway ${ }^{[91]}$.

Recently, new evidence has indicated the roles of nuclear receptors in reprogramming. Dexamethasone, a glucocorticoid steroid, can promote OSKM-induced iPSC generation 
in combination with 5 -aza ${ }^{[56]}$. It has been shown that ectopic expression of RAR $\alpha / \gamma$ and Nr5a2 greatly enhances reprogramming efficiency and kinetics, and both RARa agonist CD437 and RARY agonist AM580 significantly enhance OSKMinduced reprogramming. It has been proposed that RAR ligands bind to RAR and promote the formation of RAR/RXR heterodimers, which then bind to the Oct4 locus to activate and stabilize Oct4 expression ${ }^{[92]}$.

The mTOR pathway functions in many cellular processes, including cell growth, proliferation, differentiation, and survival. Recent studies suggest that the precise regulation of the mTOR activity plays a critical role in the successful reprogramming of somatic cells to form iPSCs ${ }^{[93]}$, and the inhibition of the mTOR pathway with rapamycin or PP242 enhances the efficiency of reprogramming ${ }^{[94]}$. Interestingly, in addition to rapamycin, other longevity-promoting compounds, including two sirtuin activators (resveratrol and fisetin), an autophagy inducer (spermidine), a PI3K (phosphoinositide 3-kinase) inhibitor (LY294002) and an antioxidant (curcumin) have also been reported to promote somatic cell reprogramming to different extents.

\section{Perspective}

Currently, target-based drug screening is still the main approach employed in new drug identification and development. Though effective in certain occasions, the overall low success rate and high development cost indicate a requirement for better approaches for identifying new therapeutic agents. Cell-based phenotypic assays represent a more physiological system and may provide better ways for drug screening and lead optimization, especially for complex diseases without a known molecular target. The development of the iPSC technology makes this approach more attractive because patient-specific iPSCs and subsequent disease-harboring tissue cells can be easily obtained for large-scale drug screening. Meanwhile, cardiomyocytes and hepatocytes derived from normal human iPSCs can be used for early toxicity evaluation, providing a more accurate and cost-effective system than many animal models. To meet these needs, the iPSC-based drug discovery platform will have to achieve safer and more efficient reprogramming, more robust directed differentiation and disease phenotyping. We summarized here that small molecule drugs can be used to improve the generation of iPSCs. Hopefully, the interplay between iPSC technology and small molecule compounds will push forward the applications of iPSC-based therapy and screening systems in the real world and eventually facilitate the development of new ways to treat diseases (Figure 1).

\section{Acknowledgements}

This work was supported by grants from the Chinese Academy of Sciences (XDA01040301) Ministry of Science and Technology of China (2009CB940900, 2010CB944900, 2011CB965104, 2011DFB30010) and the Shanghai Commission of Science and Technology (11DZ2292200).

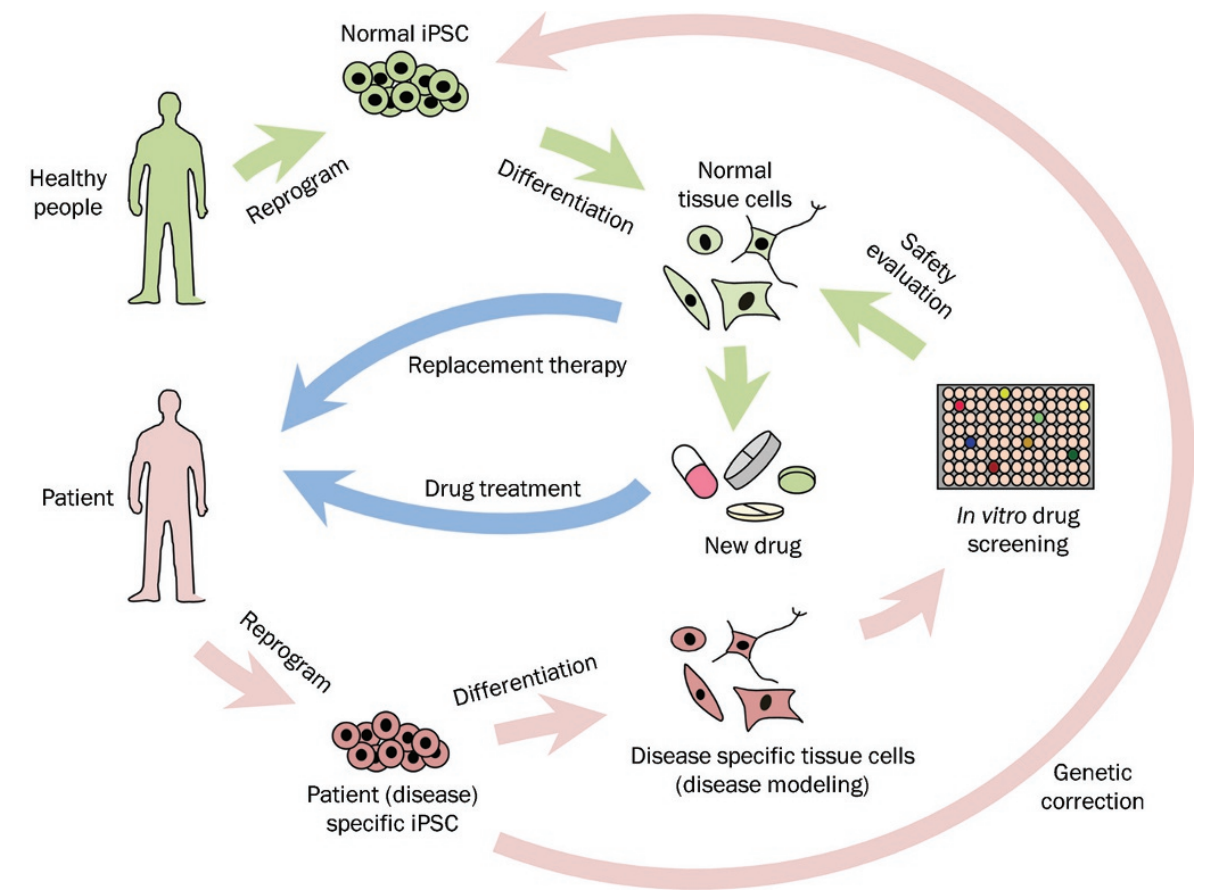

Figure 1. The use of human iPSCs in replacement therapy, disease modeling and drug development. iPSCs from healthy people can be differentiated into various normal tissue cells, which can be transferred into patients to replace the damaged cells or tissues or used for the safety evaluation of new drugs. iPSCs carrying disease-linked mutations can be derived from patients. These patient-specific iPSCs can be genetically corrected in vitro and used for autologous cell replacement therapy, or the iPSCs can be differentiated into tissue cells harboring the disease phenotype. These cells can be used to study the mechanisms of the disease and to screen new drug. 


\section{References}

1 Takahashi K, Tanabe K, Ohnuki M, Narita M, Ichisaka T, Tomoda K, et al. Induction of pluripotent stem cells from adult human fibroblasts by defined factors. Cell 2007; 131: 861-72.

2 Yu J, Vodyanik MA, Smuga-Otto K, Antosiewicz-Bourget J, Frane JL, Tian S, et al. Induced pluripotent stem cell lines derived from human somatic cells. Science 2007; 318: 1917-20.

3 Zhou T, Benda C, Dunzinger S, Huang Y, Ho JC, Yang J, et al. Generation of human induced pluripotent stem cells from urine samples. Nat Protoc 2012; 7: 2080-9.

4 Lee G, Papapetrou EP, Kim H, Chambers SM, Tomishima MJ, Fasano CA, et al. Modelling pathogenesis and treatment of familial dysautonomia using patient-specific iPSCs. Nature 2009; 461: 402-6.

5 Marchetto MC, Carromeu C, Acab A, Yu D, Yeo GW, Mu Y, et al. A model for neural development and treatment of Rett syndrome using human induced pluripotent stem cells. Cell 2010; 143: 527-39.

6 Hanna J, Wernig M, Markoulaki S, Sun CW, Meissner A, Cassady JP, et al. Treatment of sickle cell anemia mouse model with iPS cells generated from autologous skin. Science 2007; 318: 1920-3.

7 Raya A, Rodriguez-Piza I, Guenechea G, Vassena R, Navarro S, Barrero MJ, et al. Disease-corrected haematopoietic progenitors from Fanconi anaemia induced pluripotent stem cells. Nature 2009; 460: 53-9.

8 Muotri AR, Marchetto MC, Coufal NG, Oefner R, Yeo G, Nakashima $\mathrm{K}$, et al. L1 retrotransposition in neurons is modulated by MeCP2. Nature 2010; 468: 443-6.

9 Kim JB, Sebastiano V, Wu G, Arauzo-Bravo MJ, Sasse P, Gentile L, et al. Oct4-induced pluripotency in adult neural stem cells. Cell 2009; 136: 411-9.

10 Stadtfeld M, Nagaya M, Utikal J, Weir G, Hochedlinger K. Induced pluripotent stem cells generated without viral integration. Science 2008; 322: 945-9.

11 Zhou H, Wu S, Joo JY, Zhu S, Han DW, Lin T, et al. Generation of induced pluripotent stem cells using recombinant proteins. Cell Stem Cell 2009; 4: 381-4.

12 Wernig M, Zhao JP, Pruszak J, Hedlund E, Fu D, Soldner F, et al. Neurons derived from reprogrammed fibroblasts functionally integrate into the fetal brain and improve symptoms of rats with Parkinson's disease. Proc Natl Acad Sci U S A 2008; 105: 5856-61.

13 Tsuji O, Miura K, Okada Y, Fujiyoshi K, Mukaino M, Nagoshi N, et al. Therapeutic potential of appropriately evaluated safe-induced pluripotent stem cells for spinal cord injury. Proc Natl Acad Sci U S A 2010; 107: 12704-9.

14 Xu D, Alipio Z, Fink LM, Adcock DM, Yang J, Ward DC, et al. Phenotypic correction of murine hemophilia A using an iPS cell-based therapy. Proc Natl Acad Sci U S A 2009; 106: 808-13.

15 Mauritz C, Schwanke K, Reppel M, Neef S, Katsirntaki K, Maier LS, et al. Generation of functional murine cardiac myocytes from induced pluripotent stem cells. Circulation 2008; 118: 507-17.

16 Nelson TJ, Martinez-Fernandez A, Yamada S, Perez-Terzic C, Ikeda Y, Terzic A. Repair of acute myocardial infarction by human stemness factors induced pluripotent stem cells. Circulation 2009; 120: 40816.

17 Zhang J, Wilson GF, Soerens AG, Koonce CH, Yu J, Palecek SP, et al. Functional cardiomyocytes derived from human induced pluripotent stem cells. Circ Res 2009; 104: e30-41.

18 Kobayashi T, Yamaguchi T, Hamanaka S, Kato-Itoh M, Yamazaki Y, Ibata $\mathrm{M}$, et al. Generation of rat pancreas in mouse by interspecific blastocyst injection of pluripotent stem cells. Cell 2010; 142: 787 99.
19 Maehr R, Chen S, Snitow M, Ludwig T, Yagasaki L, Goland R, et al. Generation of pluripotent stem cells from patients with type 1 diabetes. Proc Natl Acad Sci U S A 2009; 106: 15768-73.

20 Bar-Nur O, Russ HA, Efrat S, Benvenisty N. Epigenetic memory and preferential lineage-specific differentiation in induced pluripotent stem cells derived from human pancreatic islet beta cells. Cell Stem Cell 2011; 9: 17-23.

21 DiMasi JA, Hansen RW, Grabowski HG. The price of innovation: new estimates of drug development costs. J Health Econ 2003; 22: 151-85.

22 Woosley RL, Cossman J. Drug development and the FDA's Critical Path Initiative. Clin Pharmacol Ther 2007; 81: 129-33.

23 Almad AA, Maragakis NJ. Glia: an emerging target for neurological disease therapy. Stem Cell Res Ther 2012; 3: 37.

24 Lunn MR, Wang CH. Spinal muscular atrophy. Lancet 2008; 371: 2120-33.

25 Ebert AD, Yu J, Rose FF Jr, Mattis VB, Lorson CL, Thomson JA, et al. Induced pluripotent stem cells from a spinal muscular atrophy patient. Nature 2009; 457: 277-80.

26 Slaugenhaupt SA, Blumenfeld A, Gill SP, Leyne M, Mull J, Cuajungco MP, et al. Tissue-specific expression of a splicing mutation in the IKBKAP gene causes familial dysautonomia. Am J Hum Genet 2001; 68: 598-605.

27 Chahrour M, Jung SY, Shaw C, Zhou X, Wong ST, Qin J, et al. MeCP2, a key contributor to neurological disease, activates and represses transcription. Science 2008; 320: 1224-9.

28 Boulting GL, Kiskinis E, Croft GF, Amoroso MW, Oakley DH, Wainger $\mathrm{BJ}$, et al. A functionally characterized test set of human induced pluripotent stem cells. Nat Biotechnol 2011; 29: 279-86.

29 Dimos JT, Rodolfa KT, Niakan KK, Weisenthal LM, Mitsumoto H, Chung $\mathrm{W}$, et al. Induced pluripotent stem cells generated from patients with ALS can be differentiated into motor neurons. Science 2008; 321: 1218-21.

30 Nguyen HN, Byers B, Cord B, Shcheglovitov A, Byrne J, Gujar P, et al. LRRK2 mutant iPSC-derived DA neurons demonstrate increased susceptibility to oxidative stress. Cell Stem Cell 2011; 8: 267-80.

31 Seibler P, Graziotto J, Jeong H, Simunovic F, Klein C, Krainc D. Mitochondrial Parkin recruitment is impaired in neurons derived from mutant PINK1 induced pluripotent stem cells. J Neurosci 2011; 31: 5970-6.

32 Yagi T, Ito D, Okada Y, Akamatsu W, Nihei Y, Yoshizaki T, et al. Modeling familial Alzheimer's disease with induced pluripotent stem cells. Hum Mol Genet 2011; 20: 4530-9.

33 Park IH, Arora N, Huo H, Maherali N, Ahfeldt T, Shimamura A, et al. Disease-specific induced pluripotent stem cells. Cell 2008; 134 : 877-86.

34 Zhang N, An MC, Montoro D, Ellerby LM. Characterization of human huntington's disease cell model from induced pluripotent stem cells. PLoS Curr 2010; 2: RRN1193.

35 Chamberlain SJ, Chen PF, Ng KY, Bourgois-Rocha F, Lemtiri-Chlieh $\mathrm{F}$, Levine ES, et al. Induced pluripotent stem cell models of the genomic imprinting disorders Angelman and Prader-Willi syndromes. Proc Natl Acad Sci U S A 2010; 107: 17668-73.

36 Yang J, Cai J, Zhang Y, Wang X, Li W, Xu J, et al. Induced pluripotent stem cells can be used to model the genomic imprinting disorder Prader-Willi syndrome. J Biol Chem 2010; 285: 40303-11.

37 Brennand KJ, Simone A, Jou J, Gelboin-Burkhart C, Tran N, Sangar $\mathrm{S}$, et al. Modelling schizophrenia using human induced pluripotent stem cells. Nature 2011; 473: 221-5.

38 Kelly M, Semsarian C. Multiple mutations in genetic cardiovascular disease: a marker of disease severity? Circ Cardiovasc Genet 2009; 2: 
182-90.

39 Carvajal-Vergara X, Sevilla A, D'Souza SL, Ang YS, Schaniel C, Lee DF, et al. Patient-specific induced pluripotent stem-cell-derived models of LEOPARD syndrome. Nature 2010; 465: 808-12.

40 Hedley PL, Jorgensen P, Schlamowitz S, Wangari R, Moolman-Smook J, Brink PA, et al. The genetic basis of long QT and short QT syndromes: a mutation update. Hum Mutat 2009; 30: 1486-511.

41 Moretti A, Bellin M, Welling A, Jung CB, Lam JT, Bott-Flugel L, et al. Patient-specific induced pluripotent stem-cell models for long-QT syndrome. N Engl J Med 2010; 363: 1397-409.

42 Itzhaki I, Maizels L, Huber I, Zwi-Dantsis L, Caspi O, Winterstern A, et al. Modelling the long QT syndrome with induced pluripotent stem cells. Nature 2011; 471: 225-9.

43 Matsa E, Rajamohan D, Dick E, Young L, Mellor I, Staniforth A, et al. Drug evaluation in cardiomyocytes derived from human induced pluripotent stem cells carrying a long QT syndrome type 2 mutation. Eur Heart J 2011; 32: 952-62.

44 Yazawa M, Hsueh B, Jia X, Pasca AM, Bernstein JA, Hallmayer J, et al. Using induced pluripotent stem cells to investigate cardiac phenotypes in Timothy syndrome. Nature 2011; 471: 230-4.

45 Davis RP, Casini S, van den Berg CW, Hoekstra M, Remme CA, Dambrot $\mathrm{C}$, et al. Cardiomyocytes derived from pluripotent stem cells recapitulate electrophysiological characteristics of an overlap syndrome of cardiac sodium channel disease. Circulation 2012; 125: 3079-91.

46 Ma D, Wei H, Lu J, Ho S, Zhang G, Sun X, et al. Generation of patientspecific induced pluripotent stem cell-derived cardiomyocytes as a cellular model of arrhythmogenic right ventricular cardiomyopathy. Eur Heart J 2012. doi: 10.1093/eurheartj/ehs226

47 Novak A, Barad L, Zeevi-Levin N, Shick R, Shtrichman R, Lorber A, et al. Cardiomyocytes generated from CPVTD307H patients are arrhythmogenic in response to beta-adrenergic stimulation. J Cell Mol Med 2012; 16: 468-82.

48 Rubin LL. Stem cells and drug discovery: the beginning of a new era? Cell 2008; 132: 549-52.

49 Laustriat D, Gide J, Peschanski M. Human pluripotent stem cells in drug discovery and predictive toxicology. Biochem Soc Trans 2010; 38: 1051-7.

50 Braam SR, Tertoolen L, van de Stolpe A, Meyer T, Passier R, Mummery CL. Prediction of drug-induced cardiotoxicity using human embryonic stem cell-derived cardiomyocytes. Stem Cell Res 2010; 4: 107-16.

51 Tanaka T, Tohyama S, Murata M, Nomura F, Kaneko T, Chen H, et al. In vitro pharmacologic testing using human induced pluripotent stem cell-derived cardiomyocytes. Biochem Biophys Res Commun 2009; 385: 497-502.

52 Zwi L, Caspi O, Arbel G, Huber I, Gepstein A, Park IH, et al. Cardiomyocyte differentiation of human induced pluripotent stem cells. Circulation 2009; 120: 1513-23.

53 Rashid ST, Corbineau S, Hannan N, Marciniak SJ, Miranda E, Alexander $\mathrm{G}$, et al. Modeling inherited metabolic disorders of the liver using human induced pluripotent stem cells. J Clin Invest 2010; 120: 3127-36.

54 Zhang S, Chen S, Li W, Guo X, Zhao P, Xu J, et al. Rescue of ATP7B function in hepatocyte-like cells from Wilson's disease induced pluripotent stem cells using gene therapy or the chaperone drug curcumin. Hum Mol Genet 2011; 20: 3176-87.

55 Papp B, Plath K. Reprogramming to pluripotency: stepwise resetting of the epigenetic landscape. Cell Res 2011; 21: 486-501.

56 Huangfu D, Maehr R, Guo W, Eijkelenboom A, Snitow M, Chen AE, et al. Induction of pluripotent stem cells by defined factors is greatly improved by small-molecule compounds. Nat Biotechnol 2008; 26 : 795-7.

57 Huangfu D, Osafune K, Maehr R, Guo W, Eijkelenboom A, Chen $\mathrm{S}$, et al. Induction of pluripotent stem cells from primary human fibroblasts with only Oct4 and Sox2. Nat Biotechnol 2008; 26: 1269-75.

58 Shi Y, Desponts C, Do JT, Hahm HS, Scholer HR, Ding S. Induction of pluripotent stem cells from mouse embryonic fibroblasts by Oct4 and Klf4 with small-molecule compounds. Cell Stem Cell 2008; 3 : 568-74.

59 Li W, Zhou H, Abujarour R, Zhu S, Young Joo J, Lin T, et al. Generation of human-induced pluripotent stem cells in the absence of exogenous Sox2. Stem Cells 2009; 27: 2992-3000.

60 Wang Q, Xu X, Li J, Liu J, Gu H, Zhang R, et al. Lithium, an antipsychotic drug, greatly enhances the generation of induced pluripotent stem cells. Cell Res 2011; 21: 1424-35.

61 Wang T, Chen K, Zeng X, Yang J, Wu Y, Shi X, et al. The histone demethylases Jhdm $1 \mathrm{a} / 1 \mathrm{~b}$ enhance somatic cell reprogramming in a vitamin-C-dependent manner. Cell Stem Cell 2011; 9: 575-87.

62 Xu X, Wang Q, Long Y, Zhang R, Wei X, Xing M, et al. Stress-mediated p38 activation promotes somatic cell reprogramming. Cell Res 2012; 23: 131-41.

63 Kim K, Doi A, Wen B, Ng K, Zhao R, Cahan P, et al. Epigenetic memory in induced pluripotent stem cells. Nature 2010; 467: 28590.

64 Polo JM, Liu S, Figueroa ME, Kulalert W, Eminli S, Tan KY, et al. Cell type of origin influences the molecular and functional properties of mouse induced pluripotent stem cells. Nat Biotechnol 2010; 28 : 848-55.

65 Liu L, Luo GZ, Yang W, Zhao X, Zheng Q, Lv Z, et al. Activation of the imprinted DIk1-Dio3 region correlates with pluripotency levels of mouse stem cells. J Biol Chem 2010; 285: 19483-90.

66 Stadtfeld M, Apostolou E, Akutsu H, Fukuda A, Follett P, Natesan S, et al. Aberrant silencing of imprinted genes on chromosome 12qF1 in mouse induced pluripotent stem cells. Nature 2010; 465: 175-81.

67 Li R, Liang J, Ni S, Zhou T, Qing X, Li H, et al. A mesenchymalto-epithelial transition initiates and is required for the nuclear reprogramming of mouse fibroblasts. Cell Stem Cell 2010; 7: 51-63.

68 Li W, Wei W, Zhu S, Zhu J, Shi Y, Lin T, et al. Generation of rat and human induced pluripotent stem cells by combining genetic reprogramming and chemical inhibitors. Cell Stem Cell 2009; 4: 16-9.

69 Maherali N, Hochedlinger K. TGFbeta signal inhibition cooperates in the induction of iPSCs and replaces Sox2 and cMyc. Curr Biol 2009; 19: 1718-23.

70 Ichida JK, Blanchard J, Lam K, Son EY, Chung JE, Egli D, et al. A small-molecule inhibitor of tgf-Beta signaling replaces sox2 in reprogramming by inducing nanog. Cell Stem Cell 2009; 5: 491-503.

71 Marson A, Foreman R, Chevalier B, Bilodeau S, Kahn M, Young RA, et al. Wnt signaling promotes reprogramming of somatic cells to pluripotency. Cell Stem Cell 2008; 3: 132-5.

72 Silva J, Barrandon O, Nichols J, Kawaguchi J, Theunissen TW, Smith A. Promotion of reprogramming to ground state pluripotency by signal inhibition. PLoS Biol 2008; 6: e253.

73 Lyssiotis CA, Foreman RK, Staerk J, Garcia M, Mathur D, Markoulaki $\mathrm{S}$, et al. Reprogramming of murine fibroblasts to induced pluripotent stem cells with chemical complementation of Klf4. Proc Natl Acad Sci U S A 2009; 106: 8912-7.

74 Varum S, Rodrigues AS, Moura MB, Momcilovic O, Easley CAt, Ramalho-Santos J, et al. Energy metabolism in human pluripotent stem cells and their differentiated counterparts. PLoS One 2011; 6: 
e20914.

75 Zhu S, Li W, Zhou H, Wei W, Ambasudhan R, Lin T, et al. Reprogramming of human primary somatic cells by OCT4 and chemical compounds. Cell Stem Cell 2010; 7: 651-5.

76 Zhang J, Khvorostov I, Hong JS, Oktay Y, Vergnes L, Nuebel E, et al. UCP2 regulates energy metabolism and differentiation potential of human pluripotent stem cells. EMBO J 2011; 30: 4860-73.

77 Evans MJ, Kaufman MH. Establishment in culture of pluripotential cells from mouse embryos. Nature 1981; 292: 154-6.

78 Martin GR. Isolation of a pluripotent cell line from early mouse embryos cultured in medium conditioned by teratocarcinoma stem cells. Proc Natl Acad Sci U S A 1981; 78: 7634-8.

79 Williams RL, Hilton DJ, Pease S, Willson TA, Stewart CL, Gearing DP, et al. Myeloid leukaemia inhibitory factor maintains the developmental potential of embryonic stem cells. Nature 1988; 336: 684-7.

80 Ying QL, Nichols J, Chambers I, Smith A. BMP induction of Id proteins suppresses differentiation and sustains embryonic stem cell selfrenewal in collaboration with STAT3. Cell 2003; 115: 281-92.

81 Ludwig TE, Levenstein ME, Jones JM, Berggren WT, Mitchen ER, Frane JL, et al. Derivation of human embryonic stem cells in defined conditions. Nat Biotechnol 2006; 24: 185-7.

82 Xu RH, Peck RM, Li DS, Feng X, Ludwig T, Thomson JA. Basic FGF and suppression of BMP signaling sustain undifferentiated proliferation of human ES cells. Nat Methods 2005; 2: 185-90.

83 Vallier L, Reynolds D, Pedersen RA. Nodal inhibits differentiation of human embryonic stem cells along the neuroectodermal default pathway. Dev Biol 2004; 275: 403-21.

84 Beattie GM, Lopez AD, Bucay N, Hinton A, Firpo MT, King CC, et al. Activin A maintains pluripotency of human embryonic stem cells in the absence of feeder layers. Stem Cells 2005; 23: 489-95.

85 Wang L, Schulz TC, Sherrer ES, Dauphin DS, Shin S, Nelson AM, et al. Self-renewal of human embryonic stem cells requires insulin-like growth factor-1 receptor and ERBB2 receptor signaling. Blood 2007; 110: 4111-9.

86 Chen S, Do JT, Zhang Q, Yao S, Yan F, Peters EC, et al. Self-renewal of embryonic stem cells by a small molecule. Proc Natl Acad Sci U S A 2006; 103: 17266-71.

87 Ying QL, Wray J, Nichols J, Batlle-Morera L, Doble B, Woodgett J, et al. The ground state of embryonic stem cell self-renewal. Nature 2008; 453: 519-23.

88 Sato N, Meijer L, Skaltsounis L, Greengard P, Brivanlou AH. Maintenance of pluripotency in human and mouse embryonic stem cells through activation of Wnt signaling by a pharmacological GSK-3specific inhibitor. Nat Med 2004; 10: 55-63.

89 Banito A, Rashid ST, Acosta JC, Li S, Pereira CF, Geti I, et al. Senescence impairs successful reprogramming to pluripotent stem cells. Genes Dev 2009; 23: 2134-9.

90 Hong $\mathrm{H}$, Takahashi K, Ichisaka T, Aoi T, Kanagawa O, Nakagawa M, et al. Suppression of induced pluripotent stem cell generation by the p53-p21 pathway. Nature 2009; 460: 1132-5.
91 Esteban MA, Wang T, Qin B, Yang J, Qin D, Cai J, et al. Vitamin C enhances the generation of mouse and human induced pluripotent stem cells. Cell Stem Cell 2010; 6: 71-9.

92 Wang W, Yang J, Liu H, Lu D, Chen X, Zenonos Z, et al. Rapid and efficient reprogramming of somatic cells to induced pluripotent stem cells by retinoic acid receptor gamma and liver receptor homolog 1. Proc Natl Acad Sci U S A 2011; 108: 18283-8.

$93 \mathrm{He} \mathrm{J}$, Kang L, Wu T, Zhang J, Wang H, Gao H, et al. An elaborate regulation of mammalian target of rapamycin activity is required for somatic cell reprogramming induced by defined transcription factors. Stem Cells Dev 2012; 21: 2630-41.

94 Chen T, Shen L, Yu J, Wan H, Guo A, Chen J, et al. Rapamycin and other longevity-promoting compounds enhance the generation of mouse induced pluripotent stem cells. Aging Cell 2011; 10: 908-11.

95 Urbach A, Bar-Nur O, Daley GQ, Benvenisty N. Differential modeling of fragile $X$ syndrome by human embryonic stem cells and induced pluripotent stem cells. Cell Stem Cell 2010; 6: 407-11.

96 Ku S, Soragni E, Campau E, Thomas EA, Altun G, Laurent LC, et al. Friedreich's ataxia induced pluripotent stem cells model intergenerational GAATTC triplet repeat instability. Cell Stem Cell 2010; 7: 631-7.

97 Camnasio S, Delli Carri A, Lombardo A, Grad I, Mariotti C, Castucci $A$, et al. The first reported generation of several induced pluripotent stem cell lines from homozygous and heterozygous Huntington's disease patients demonstrates mutation related enhanced lysosomal activity. Neurobiol Dis 2012; 46: 41-51.

98 Soldner F, Hockemeyer D, Beard C, Gao Q, Bell GW, Cook EG, et al. Parkinson's disease patient-derived induced pluripotent stem cells free of viral reprogramming factors. Cell 2009; 136: 964-77.

99 Fujikura J, Nakao K, Sone M, Noguchi M, Mori E, Naito M, et al. Induced pluripotent stem cells generated from diabetic patients with mitochondrial DNA A3243G mutation. Diabetologia 2012; 55: 1689-98.

100 Hamasaki M, Hashizume Y, Yamada Y, Katayama T, Hohjoh H, Fusaki $\mathrm{N}$, et al. Pathogenic mutation of ALK2 inhibits induced pluripotent stem cell reprogramming and maintenance: mechanisms of reprogramming and strategy for drug identification. Stem Cells 2012; 30: 2437-49.

101 Cheng LT, Nagata S, Hirano K, Yamaguchi S, Horie S, Ainscough J, et al. Cure of ADPKD by selection for spontaneous genetic repair events in Pkd1-mutated iPS cells. PLoS One 2012; 7: e32018.

102 Shi Y, Do JT, Desponts C, Hahm HS, Scholer HR, Ding S. A combined chemical and genetic approach for the generation of induced pluripotent stem cells. Cell Stem Cell 2008; 2: 525-8.

103 Lin T, Ambasudhan R, Yuan X, Li W, Hilcove S, Abujarour R, et al. A chemical platform for improved induction of human iPSCs. Nat Methods 2009; 6: 805-8.

104 Watanabe K, Ueno M, Kamiya D, Nishiyama A, Matsumura M, Wataya $\mathrm{T}$, et al. A ROCK inhibitor permits survival of dissociated human embryonic stem cells. Nat Biotechnol 2007; 25: 681-6. 